\title{
Simulation on Temperature and Ampacity of Mining Flame-proof High Voltage Cable Connector
}

\author{
Haiying $\mathrm{Li}^{1, a}$, Zhuocheng Xue ${ }^{1}$ and Jiancheng Song ${ }^{2}$ \\ ${ }^{1}$ Department of Electrical Engineering, University of Shanghai for Science and Technology, Yangpu District, Shanghai 200093, China \\ ${ }^{2}$ College of Electrical and Power Engineering, Taiyuan University of Technology, Taiyuan 030024, Shanxi Province, China
}

\begin{abstract}
To investigate the accident causes of mining flame-proof high voltage (F-HV) cable connector, the temperature and ampacity of LBG1-200/6 high voltage cable connector are analyzed. At first, the material properties and structure of connector are introduced from the aspects of electrical, insulation and thermal. Then the electromagnetic field and thermal field coupling model of cable connector are established by the finite element method. Finally, in the numerical examples, temperature distribution and ampacity change caused by power harmonics, dielectric loss and slight structure change are quantitatively plotted and analyzed. The paper provides great insight into the security operation of F-HV cable connector
\end{abstract}

\section{Introduction}

F-HV cable connector is used in $6-10 \mathrm{kV}$ mining transmission line per 300 500m. These connectors experience power harmonics, insulation aging and slight structure change in operation. In addition, F-HV cable connectors are enclosed with limited volume. Heat accumulation easily leads to explosion. The proportion of cable connector accidents is up to $70 \%$ of cable accidents [1]. The temperature and ampacity of cable connectors are important parameters to evaluate the potential vulnerability.

Numerous thermal behaviors on enclosed space have been reported. Gas isolated switchgear (GIS) is an enclosed equipment. Its heat issues and power losses are analyzed by combining the electric-magnetic field and thermal-fluid field [2]. The air flow on temperature distribution is further discussed [3]. Joint bay of high voltage cables in power systems is another kind of enclosed equipment. Its temperature rise is studied by the finite element method [4]. The above research lays the foundation for temperature and ampacity analysis of FHV cable connector. However, F-HV cable connectors have many unique features. (1) Mining cable is flame retardant with special shielding layers to resist crush and hit. Its structure is different from power cable, so the structure of connector is unique. (2) Load fluctuates frequently in mining activities. The connector expands with heat and contracts with cold, which causes slight structure change. Additional heat is generated. (3) Wide application of inverters in the mine brings high proportion harmonics. The extra temperature rise by harmonic currents can't be ignored [5]. (4) Connectors run in the environment with $100 \%$ relative humidity all

\footnotetext{
${ }^{\mathrm{a}}$ Corresponding author: sh_lhy@163.com
}

year round. Insulation aging is common due to the interaction among electricity, heat and humidity. The extra temperature rise by dielectric losses should be considered [6].

In this paper, temperature and ampacity of F-HV cable connector are investigated with consideration to power harmonics, dielectric loss and slight structure change. Electric-magnetic-heat coupling method and ANSYS software are adopted. It will provide great insight into the design, type selection and fault analysis of cable connector.

\section{F-HV cable connector}

LBG1-200/6 F-HV cable connector is widely used in the mine. Its geometry size is shown in Table 1.

\begin{tabular}{lll}
\multicolumn{2}{l}{ Table 1. Geometry size of the high voltage cable connector. } \\
\hline Materials & $\begin{array}{l}\text { Thickness } \\
(\mathrm{mm})\end{array}$ & $\begin{array}{l}\text { Thermal } \\
\text { conductivity } \\
\left(\mathrm{W} /\left({ }^{\circ} \mathrm{C} \cdot \mathrm{m}\right)\right)\end{array}$ \\
\hline Brass core & 10 & 109 \\
DMC layer & 5 & 2.5 \\
DMC insulator & $/$ & 2.5 \\
Internal air gap & 3 & 0.026 \\
External air gap & 4 & 0.026 \\
Cast iron shell & 10 & 32 \\
\hline
\end{tabular}

${ }^{\mathrm{b}}$ Diameter of brass core.

Brass core is the conductor of cable connector with low resistivity, cheap price, high hardness and good antioxidation. It is insulated by dough molding compounds (DMC). DMC is dyed red to warn high voltage.

LBG1-200/6 F-HV cable connector using DMC makes itself with fine insulation property. Compared with 
other resin-composite, DMC has better characteristics [7]. (1) Withstanding voltage is up to $36 \mathrm{kV}$. (2) Resistivity is $10^{12} \Omega \cdot \mathrm{m}$, even in high humidity condition. (3) Flame retardation and anti-arc capacities are advanced. Thermal deformation temperature (TDT) is high. It's the best choice in the environment with high density gas. Its detail physical properties are shown in Table 2. In addition, to enhance the insulation, internal air gap is employed to ensure the creepage distance.

Table 2. Physical properties of DMC.

\begin{tabular}{lll}
\hline Properties & Value & Units \\
\hline Resistivity & $10^{12}$ & $\Omega \cdot \mathrm{m}$ \\
Conductivity & 2.5 & $\mathrm{~W} /\left({ }^{\circ} \mathrm{C} \cdot \mathrm{m}\right)$ \\
Anti-arc & 180 & $\mathrm{~s}$ \\
Work temperature & 130 & ${ }^{\circ} \mathrm{C}$ \\
TDT & 220 & ${ }^{\circ} \mathrm{C}$ \\
\hline
\end{tabular}

To meet the technical requirements of thermal performance, air gap is designed. (1) Internal and external air gap can prevent the heat from transferring to the outer layer. The temperature difference between the connector shell and the cable is avoided. (2) Air gap can act as heat buffer when transient peak currents pass. The temperature rise of the shell is constrained to avoid fire accidents. Simplified cross-section is shown in Figure 1.

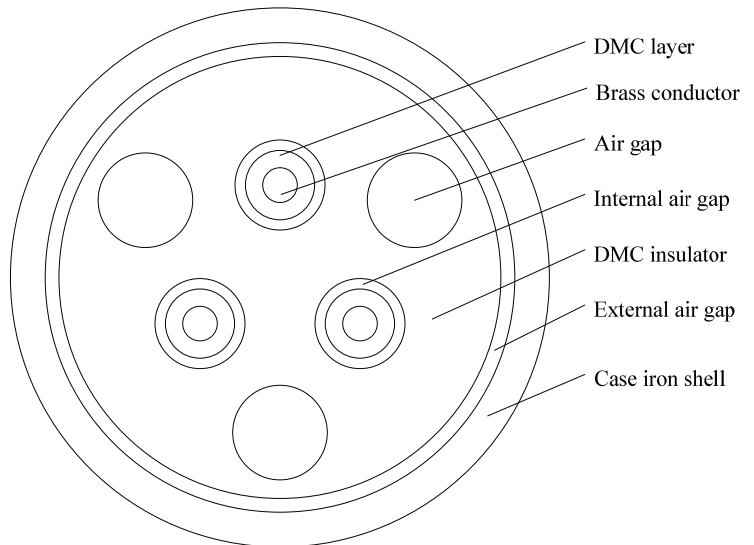

Figure 1. Simplified cross-section of F-HV cable connector.

$\mathrm{DMC}$ and cable connector combine many advantages, but their physical properties still may change irreversibly due to contacting with AC currents in its long service period. Slight structure change, insulation aging and harmonic currents happen frequently in manufacture or in operation. Slight structure change increases heat accumulation. Insulation aging in DMC causes dielectric losses. Harmonics bring extra power losses. Extra temperature rise and reduced ampacity make the connector vulnerable.

\section{ANSYS simulation}

Electromagnetic-thermal coupling model [8] in ANSYS software is adopted to analyze the temperature rise and ampacity of LBG1-200/6 F-HV cable connector. The impacts of harmonics, dielectric loss and slight structure change are incorporated.

\subsection{Electromagnetic-thermal coupling model}

Physical environment method [9] is selected to build the electromagnetic field and thermal field. The current is loaded in the electromagnetic field. The relative parameters, such as power and electric-magnetic distribution, are obtained. These results treated as thermal sources are loaded in the thermal field. The temperature distribution is gotten. The solver for electromagnetic field is unit Plane53. The solver for thermal field is unit Plane77. Unit Plane230 is used to analyze insulation aging via dielectric permittivity and dissipation factor parameters. The resistivity of the conductor is varying with temperature, so the temperature is determined by iteration method.

\subsection{Key instructions in simulation}

(1) Concentric circles in the model overlap together. Before define the material property for every layer of the model, overlap instruction should be used to make the concentric circle separated. Otherwise mistakes by overlap will happen. (2) To plot the finite elements, more elements will result in slow calculation speed, fewer elements will affect the accuracy. In practice, increase the number of elements until the results will not change obviously. The number of finite elements in this model is set to 20. (3) The voltage degrees of freedom in the model require coupling to ensure the conductor integrated. Then select one finite element to load the current, the integrated conductor is loaded simultaneously. Three phase angular differences are $120^{\circ}$. (4) In insulation aging analysis, result file (.rst) can't be generated in electric field. To couple with thermal field, heat generation rate is output by instruction *get. Command flow is programmed to calculate the temperature distribution.

\section{Numerical examples}

\subsection{Ampacity analysis}

Ampacity is the current in amperes when the steady temperature of electrical conductor reaches $90^{\circ} \mathrm{C}$ based on standard IEC 60287 [10]. Load rated current 200A to LBG1-200/6 F-HV cable connector in ANSYS software, the temperature distribution by electromagnetic-thermal analysis is shown in Figure 2. We can see the highest temperature is $90.2^{\circ} \mathrm{C}$, so its design fits for the security standard.

\subsection{Harsh environments analysis}

Harsh Environments refer to harmonic currents and dielectric losses. Harmonics in the mine are brought by powerful equipments $[11,12]$. Harmonic currents proportions are $\{200,0.3125,0.1563,0.09375\}$ obtained from the investigation. That means fundamental current is $200 \mathrm{~A}$, the third harmonic current is $62.5 \mathrm{~A}$, the fifth harmonic current is $31.26 \mathrm{~A}$ and the seventh harmonic 
current is $18.75 \mathrm{~A}$. The temperature distribution in harmonic environment is shown in Figure 3.

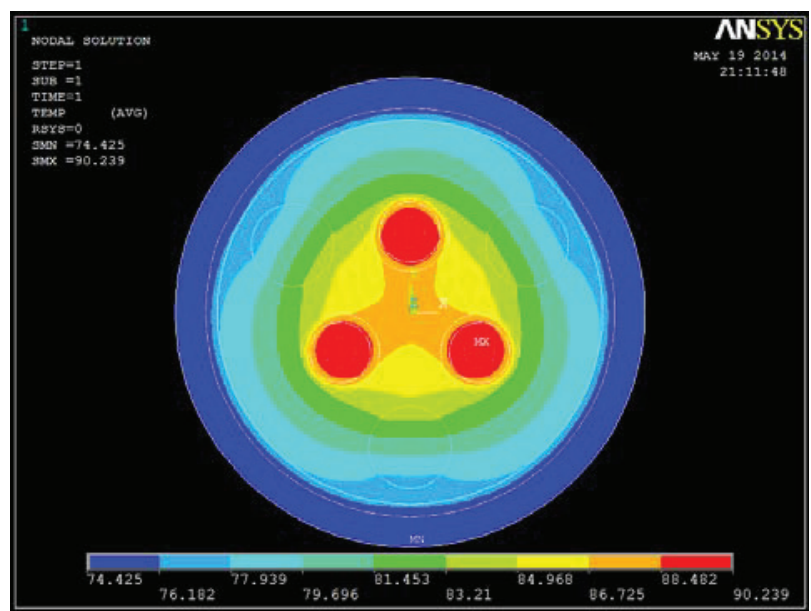

Figure 2. Temperature distribution of F-HV cable connector in rated condition.

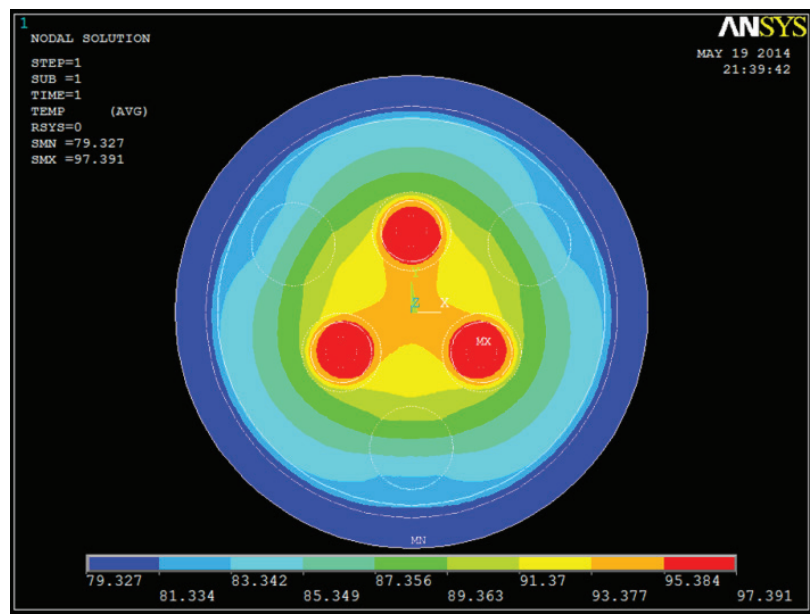

Figure 3. Temperature distribution of F-HV cable connector in harmonic environment

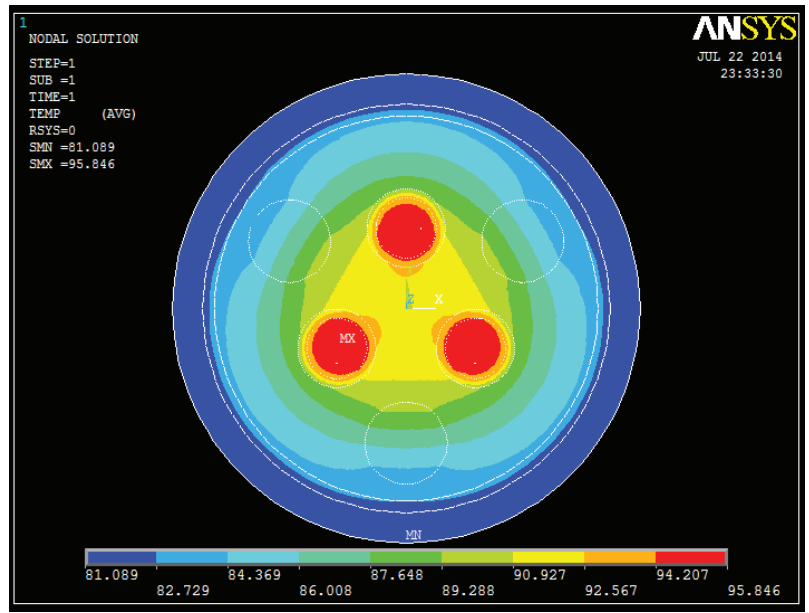

Figure 4. Temperature distribution of F-HV cable connector in aging environment.

From Figure 3, we can see the temperature of conductor is up to $97.4^{\circ} \mathrm{C}$ and the temperature of shell is $79.3^{\circ} \mathrm{C}$ affected by the harmonic currents. The temperature is far beyond the security temperature. If the connector works long in such case, the accidents easily happen.

In addition, dielectric losses can't be ignored since DMC properties change in its long service period. In normal case, the relative dielectric constant is 3.6 4.3 and dielectric loss $\operatorname{tg} \delta$ is 0.0129 . In aging case, the relative dielectric constant increases to 5.0 and dielectric $\operatorname{loss} \operatorname{tg} \delta$ increases to 0.03 [13]. The temperature distribution in aging environment is shown in Figure 4.

From Figure 4, we can see the temperature of conductor is up to $95.8^{\circ} \mathrm{C}$ and the temperature of shell is $81.1^{\circ} \mathrm{C}$ affected by the insulation aging. Emphasize here the temperature difference exists between the connector and the cable in this case. The insulation breakdown will happen.

\subsection{Slight structure change analysis}

Air gap has great effect on heat radiation. However, external air gap can't keep the design size even in manufactory process [14].

\subsubsection{Effect on temperature}

The initial design size of external air gap is $4 \mathrm{~mm}$. To discuss its impact, load rated current but adjust the thickness of air gap. The air gaps are varying from $3 \mathrm{~mm}$ to $6 \mathrm{~mm}$. The temperature distributions for the conductor and the shell are shown in Figure 5 and Figure 6.

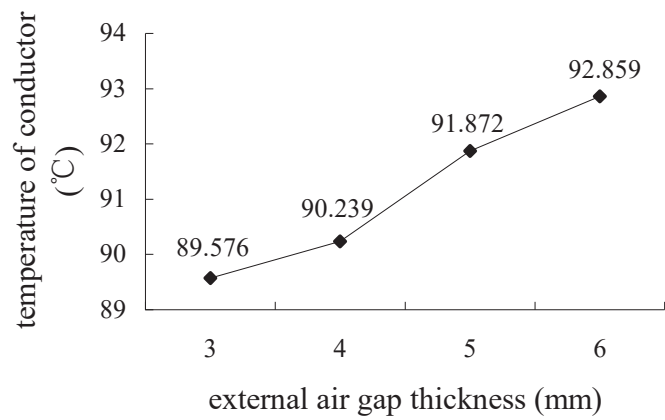

Figure 5. Temperature distribution of the conductor.

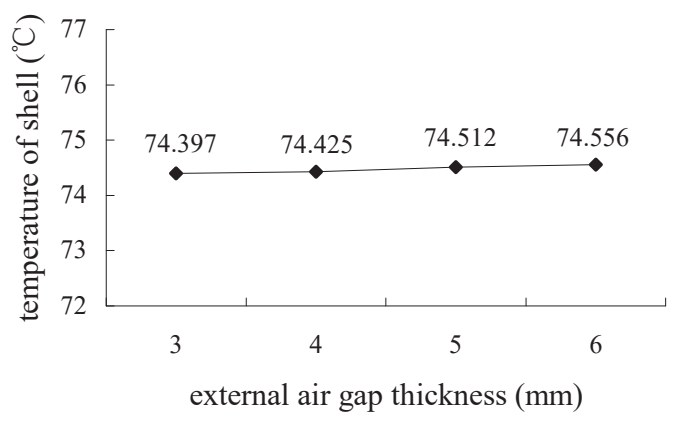

Figure 6. Temperature distribution of the shell.

From Figure 5, we can see the thicker the air gap, the higher the temperature. High thermal conductivity of air gap prevents the internal heat from transferring. The temperature rise is about $2.6^{\circ} \mathrm{C}\left(92.859^{\circ} \mathrm{C}-90.239^{\circ} \mathrm{C}\right)$. 
Structure change incorporating the harmonics and aging makes the temperature higher. These phenomena explain the reason that some connector accidents happened in non-full load case.

From Figure 6, we can see the temperature of the shell increases only $0.16^{\circ} \mathrm{C}$. This is because the heat accumulates in the air gap layer. The effect of structure change mainly acts on the temperature of conductor.

\subsubsection{Effect on ampacity}

Structure change constrains heat transfer, thus it will affect the ampacity directly. The ampacities with different thickness are shown in Table 3.

Table 3. Relationship between air-gap thickness and ampacity

\begin{tabular}{lll}
\multicolumn{3}{c}{ under safe temperature. } \\
\hline $\begin{array}{l}\text { Thickness } \\
(\mathrm{mm})\end{array}$ & Ampacity $^{\mathrm{c}}(\mathrm{A})$ & $\begin{array}{l}\text { Difference ration of } \\
\text { ampacity and rated } \\
\text { current }\end{array}$ \\
\hline 3 & 203.1 & $+1.55 \%$ \\
4 & 200.0 & $/$ \\
5 & 196.6 & $-1.7 \%$ \\
6 & 193.4 & $-3.3 \%$ \\
\hline${ }^{\mathrm{c}}$ RMS of current.
\end{tabular}

From Table 3, we can see the thicker the air gap, the lower the ampacity. To ensure the security, reducing operating current is the common measure. Improving ventilation and monitoring temperature are also necessary for the connector in such harsh environments.

\section{Conclusion}

The research on LBG1-200/6 F-HV cable connector shows the conclusions as follows. In rated condition, internal air gap design keeps the temperature of connector and cable identical. When harmonics are superposed, RMS value increases and temperature rise is up to $7.4^{\circ} \mathrm{C}$. Dielectric loss of DMC will bring additional $5.8^{\circ} \mathrm{C}$ temperature rise, even temperature difference with the cable. Slight structure change will further intensify the condition. The ampacity decreases obviously. The research provides insight into accident causes and ampacity analysis of other type connectors.

\section{Acknowledgments}

This work was financially supported by Key Laboratory of Mining Electrical Equipment and Intelligent Control (Taiyuan University of Technology), Shanxi, China (MEI201601).

\section{References}

1. JW Qi and JC Song, Industry and Mine Automation, 12, 32 (2009) (In Chinese)

2. H K Kim Y H Oh and S H Lee, T and D Asia (NJ: IEEE Computer Society, 2009)
3. J Lei, JY Zhong, SJ Wu, Z Wang, YJ Guo and XY Qin, Journal of Electrical Engineering and Technology, 11, 781(2016)

4. J A Pilgrim, D J Swaffield, P L Lewwin, S T Larsen and D Payne, IEEE Trans. on Power Delivery, 24, 1029(2009)

5. CY Li, J Chen, $\mathrm{LB} \mathrm{Hu}$ and JY Cao, 12th IET Int. Conf. on $A C$ and DC Power Transmission (Institution of Engineering and Technology, 2016)

6. B Zhu, ZD Jia, Y Yuan, G J Lu, W N Fang and Z C Guang, IEEE 11th Int. Conf. on the Properties and Applications of Dielectric Materials (Institute of Electrical and Electronics Engineers Inc., 2015)

7. $\mathrm{W} \mathrm{L} \mathrm{Wu}$ and Y S Feng, Int. Conf. on Advanced Fibers and Polymer Materials (Chemical Industry Press, 2009)

8. HY Li, YC Liu and JC Song, High Voltage Apparatus, 50, 82(2014) (In Chinese)

9. A Sedaghat and D L Francisco, IEEE Transactions on Power Delivery, 29, 2306(2014)

10. S Dubitsky, G Greshnyakov and N Korovkin, IEEE Int. Energy Conf. (Institute of Electrical and Electronics Engineers Inc., 2016)

11. A Hiranandani, IEEE Industry Applications Magazine, 4, 42(1998)

12. D Charis, P L Dimitris, S D Petros and G Kostas, IEEE Transactions on Power Delivery, 22, 584(2007)

13. DH Wu, Fiber Reinforced Plastics/Composites, 6, 19(1996) (In Chinese)

14. Y Kong, Engineering Plastics Application, 28, 21(2000) (In Chinese) 